\title{
Cultural practices on infant feeding and nursing- mothers' adoption of exclusive breastfeeding practice in Imo state Nigeria
}

\begin{abstract}
The aim of this study was to determine the influence of cultural practices on infant feeding on adoption of exclusive breastfeeding practice by nursing-mothers in selected communities in Imo State Nigeria. A descriptive study design was employed to elicit information from 340 nursing-mothers from three selected communities in the state. The target population of the study was all the 405 nursing-mothers with children aged twenty-four months and below in the selected communities. Instruments for data collection were structured questionnaire and Focus Group Discussion (FGD) and the reliability of the instrument was established $(\mathrm{r}=0.8)$. Ten nursing mothers from each of the communities participated in FGD. Results of the study revealed that exclusive breastfeeding practice was $13.5 \%$ in the target communities. First fluid given to infant after birth $(\mathrm{P}=0.001)$, Timing of first fluid given to infant $(\mathrm{P}$-value $=0.04)$, duration of breastfeeding before commencing weaning $(\mathrm{P}<0.0001)$ and most popular practice of infant feeding in the first six months of life $(\mathrm{P}=0.001)$ were statistically significant, while beliefs about colostrum $(\mathrm{P}=0.067)$ and culture being opposed to exclusive breastfeeding $(\mathrm{P}=0.34)$ were not statistically significant. The study concluded that breastfeeding is an embodied practice that is strongly rooted in culture which could contribute to the slow progress recorded in the adoption of exclusive breastfeeding. There is need to expand the current strategies employed in the promotion of exclusivebreastfeeding to include cultural perspective.
\end{abstract}

Keywords: culture, infant, feeding-practices, exclusive-breastfeeding, honey, jiggery, ghutti, nutrition, child birth, medicinal herb, medicinal root, ocimum gratissimum, garcinia kola
Volume 5 Issue 5 - 2017

\author{
Ibe SNO,' Obasi O, ${ }^{2}$ Nwoke EA,' Nwufo \\ CR,' Ebirim ClC,' Osuala EO, ${ }^{3}$ Amadi CO,' \\ Ezenwuba $\mathrm{CO}^{4}$ \\ 'Department of Public Health, Federal University of Technology, \\ Nigeria \\ 2Department of Sociology, Imo State University, Nigeria \\ ${ }^{3}$ Deptment of Nursing Science, Nnamdi Azikiwe University \\ Nnewi Campus, Nigeria \\ ${ }^{4}$ Deptment of Nursing Science, Imo State University Owerri, \\ Nigeria
}

Correspondence: Ibe SNO, Department of Public Health, Federal University of Technology, Owerri Nigeria, Tel 234(0)803 675 1743,Email sallyibe@yahoo.com

Received: March 28, 2017 | Published: April 13, 2017
Abbreviations: FGD, focus group discussion; EBF, exclusive-breast feeding practice; CDOs, community development officers; LGAS, local government areas; SPSS, statistical package for the social science

\section{Introduction}

Adoption of exclusive-breastfeeding practice (EBF) by nursingmothers in Nigeria has remained an issue of great concern to EBF promoters. Breastfeeding is a universal practice among humans and indeed all mammals. The practice of breastfeeding an infant is one of the sex roles of the female human which is as old as humanity. It is indeed an integral part of the reproductive process but has a cultural bias. According to Stuart-Macadam \& Dettwyler, ${ }^{1}$ breastfeeding in humans is not only a biological process but also a culturally determined behaviour. The cultural practices of infant feeding vary from culture to culture and relate to types of supplementary and complementary feeds, time of initiation of breastfeeding, frequency of breastfeeding and duration of breastfeeding among others. Culture refers to values, beliefs, norms and practices of a particular group which are learned, shared and which guide attitudes, decisions and actions in a patterned way. ${ }^{2}$ Wide range of factors come into play when deciding on infant feeding practice and in all cultures there are factors that affect the decision of women on infant feeding. ${ }^{3}$ Adequate nutrition during infancy and childhood is fundamental to good health and the development of the full potential of the child. ${ }^{4-7}$ Breastfeeding is the best method of providing superior nutrition required for the healthy growth and development of the infant. In an effort to achieve successful breastfeeding globally, the World Health Organization in $^{8}$ recommended EBF of infants for 4-6months. ${ }^{9}$ In the year 2001 EBF was pegged at six months, though mothers were required to continue breastfeeding with adequate complementary feed for up to twoyears. ${ }^{10} \mathrm{EBF}$ hence became an innovation and a new orientation to infant feeding practice which differed from the traditional practice of breastfeeding with addition, which could be water, herbs or other forms of fluids that were introduced to the infant right from birth, in line with cultural beliefs and practices. Exclusive breastfeeding (EBF) is the feeding of an infant with breast milk (including expressed breast milk) only, without any food or drink, nor even water except drops or syrups consisting of vitamins, minerals supplements or medicines when medically prescribed. ${ }^{5,8}$ It is therefore a positive change as it was credited for reducing infant mortality. ${ }^{11,12}$ Despite the benefits of EBF and efforts made to encourage and support the practice by international and national agencies the rate still remained low globally, ${ }^{13}$ with Nigeria having compliance rate of 13 percent,${ }^{14}$ which was below the WHO/UNICEF target of 75 percent and above. ${ }^{1}$ Low EBF practice had persisted longer than expected as the situation had not changed significantly globally.

A study of Hong Kong mothers reported that 44 percent of mothers intending to exclusively breastfeed their child for the first six months of life had stopped doing so within 6 weeks. ${ }^{15}$ Similarly, another study conducted in the year 2000 by the Hong Kong Department of Health found that only about 10 percent of women practiced exclusive breastfeeding as recommended by WHO for the first 6 months of baby's life. ${ }^{16,17}$ Found average level of breastfeeding 
initiation immediately after child birth to be 45 percent and within two hours after birth to be 29 percent among breastfeeding mothers in Southwest Nigeria (Yorubas). It should therefore be appreciated that generally wide range of factors come into play when deciding on infant feeding practice and in all cultures there were factors that affect the decision of women on infant feeding. ${ }^{3,18}$ Reported that mothers in La Paz Bolivia who were discarding colostrum and using pre-lacteal feeds and who attributed the practice to ethnic and cultural differences were less likely to exclusively breastfeed for a longer duration. Agunbiade \& Ogunleye ${ }^{17}$ reported as constraints to EBF the practice among breastfeeding mothers in Southwest Nigeria, the traditional child feeding practices such as feeding infants with herbal concoction which was still common among the Yorubas. The cultural influences differed from one society to another and some of them negatively affect proper feeding routine of children especially in developing countries. ${ }^{19}$ Davies-Adetugbo ${ }^{20}$ opined that the low rate of exclusive breastfeeding in Nigeria may, in part, be due to traditional beliefs, practices and rites and cited the Yoruba and Bini communities where exclusive breastfeeding is considered dangerous to the health of the infant who was thought to require water to quench thirst or stop hiccoughs. Furthermore, Patil et al., ${ }^{21}$ reported that prelacteal feeds were given by 34.5 percent of mothers and common feeds were honey, jiggery, ghutti (a powdered mixture containing herbs). In Kenya, water and juice were introduced to the infant's diet in the first month of life and other foods by the second and third month of life despite prolonged breastfeeding. ${ }^{22}$ In Peru infants were weaned early by the third month of birth. ${ }^{23}$ In certain European cultures only about 30 percent of mothers still breastfed by the third month after delivery. ${ }^{24}$ There was need to understand breastfeeding practice in the context of the cultural system. The cultural influences on EBF practice had not been adequately considered by researchers, which had resulted in not taking breastfeeding as a complex process influenced by social and cultural forces. ${ }^{25}$ This study was a contribution to the bridging of this observed gap and the research results presented in this report were delimited to those relating to cultural practices on infant feeding and nursing-mothers adoption of exclusive breastfeeding practice. It is an excerpt from a more extensive study that determined "Factors influencing the adoption of exclusive breastfeeding practice by nursing-mothers in selected rural communities in Imo State, Nigeria". Some excerpts of the main study addressing other variables other than those reported in this paper had earlier been published in other journals. The target population was nursing-mothers who had children aged 24 months and below in the selected communities (Umuokanne, Umuowa and Avutu) in Imo State. The independent variables of interest were limited to those relating to cultural practices on infant feeding (first fluid given to new born, type and timing of first fluid, normal duration for weaning an infant); belief about colostrum; most popular practice of infant feeding in the community and if culture was opposed to exclusive breastfeeding practice. The dependent variables were time of initiating breastfeeding, length of time infant spends on breast during breastfeeding, breastfeeding on demand including at night, rooming-in (sleeping with the child), time of introduction of supplementary and complementary feeds and duration of breastfeeding before weaning.

\section{Methodology}

A descriptive survey design was utilized for this study and the communities were selected through purposive sampling method based on their being rural communities and located in the different geopolitical (senatorial) zones of the state. Community entry was facilitated by the Community Development Officers in the LGAs and community leaders consented to the study. All nursing-mothers in these communities were targeted and the households were visited for eligible respondents. The target population of the study was 405 nursing-mothers with children aged twenty-fourmonths and below in the three selected communities. The target population was made up of 118 nursing-mothers from Dikenta-na-Odinma community, 125 from Umuowa community and 162 from Umuokanne community. However, a total of 340 nursing mothers $(84 \%$ of the target population) responded to the questionnaire. The rest were either not found at home when visited or declined participation. The distribution of respondents by their communities was as follows: $107(91 \%)$ of the target population in Dikenta na Odinma community, $111(89 \%)$ of the target population in Umuowa community and 122 (75\%) of the target population in Umuokanne community. This was representative of the target population. In addition 30 nursing-mothers participated in the Focus Group Discussion (FGD), (10 from each of the three communities). The theme for FGD was 'barriers to exclusive breastfeeding practice'. The study took place between December, 2012 and June, 2013. Data were collected with the assistance of eight trained Research Assistants and the Community Development Officers (CDOs) in the various Local Government Areas (LGAs). They assisted in community entry and also served as principal guides in the communities. The instruments for data collection were structured questionnaire and Focus Group Discussion (FGD) guide developed by the researchers. The FGD guiding question was the constraint to the practice of exclusive-breastfeeding by nursingmothers in the community? Particular to this section was the reason for the addition to breast milk in the first six months of life. Reliability of the instrument was established with Crombach's alpha coefficient reliability test and the value was 0.8 . Data were analysed using the Statistical Package for the Social Sciences (SPSS) computer software package (version 16.0). Statistical analytic techniques used were frequency counts and percentages. Chi-square $\left(\mathrm{X}^{2}\right)$ statistics was employed to test hypotheses for associations. The FGD was translated and transcribed by the researchers. The decision rule was to accept the alternate hypothesis ( $\mathrm{H} 1)$ set for this study if P-value was significant $(\mathrm{P}<0.05)$ and reject $\mathrm{H} 1$ if $\mathrm{P}$-value was $>0.05$ level of significance.

\section{Result}

\section{Age of nursing mother and practice of EBF}

Ages of the nursing-mothers were between 15years and 49years, with more mothers $98(28.8 \%)$ in the 35-39years age group, 92(27.1\%) in the $30-34$ years age group, $71(20.9 \%)$ in the $25-29$ years age group, $43(12.6 \%)$ in the 20 -24years age group, $22(6.5 \%)$ in the 40-44years age group, $8(2.4 \%)$ in the $45-49$ years age group and $6(1.8 \%)$ in the 15-19years age group. Results of this study revealed that only $2(33.3 \%)$ out of 6 respondents aged 15-19years, 3(7.0\%) out of 43 aged 20 -24years, $7(9.9 \%)$ out of 71 aged 25 -29years, $9(9.8 \%)$ out of 92 aged 30-34years, $16(16.3 \%)$ out of 98 aged 35-39years, 7(31.8\%) out of 22 aged $40-44$ years and $2(25.0 \%)$ out of 8 aged $45-49$ years practised EBF. In all the age groups greater percentage of the nursingmothers did not practice EBF and age of nursing-mothers had statistically significant relationship with practice of EBF by nursingmothers' $(\mathrm{P}=0.038)$.

\section{First fluid culturally given to new born and the adoption EBF practice}

Results in Table 1 showed that 95 nursing-mothers (27.9\%) responded that the first fluid given to infants after birth in the community was warm water, while $90(26.5 \%)$ reported that the first 
fluid was water containing agbeilu (Garcinia Kola) popularly called bitter-kola. Some nursing mothers $48(14.1 \%)$ said water containing utazi leaf (Gongronema Latifolium) extract, while 44(12.9\%) mothers said breast milk. Other responses included water with palm fruit extract $13(3.8 \%)$, gripe water $13(0.3 \%)$, water containing ochamala (root extract) $3(0.9 \%)$, water containing nchuawu (ocimum gratissimum) $7(2.1 \%)$, Nine $(2.6 \%)$ were grouped as others and they named such fluids as water containing other traditional herbs and roots such as mbaji leaf (medicinal herb); otonehihie (medicinal root) and palm wine which was said to be given in situations where the breasts were yet to produce milk or where the mother died immediately after child birth. Only one $(2.3 \%)$ nursing-mother out of 44 who said that the first fluid culturally given to new born infant was only breast milk, one $(4.0 \%)$ nursing-mother out of 25 who said breast milk and warm water, $19(20.0 \%)$ out of 95 who responded that the first fluid was warm water only, 2(4.2) out of 48 who said warm water containing utazi leaf, one $(14.3 \%)$ out of 7 who said water containing nchuawu and $22(37.5 \%)$ out of 90 who said warm water containing agbeilu practised EBF, while none of the rest who gave other responses such as artificial milk, gripe water, water containing ochamala root extract, water with palm fruit extract, mbaji leaf, otonaehihe root practised EBF. There was no significant relationship between the nursingmothers' response on first fluid given to the infant after birth and nursing mothers' adoption of EBF practice (chi-square value $=30.66$, $\mathrm{df}=12$ and $\mathrm{P}=0.001)$ as shown in Table 1.

Table I First fluid given to a new born in the community and nursing-mothers adoption of EBF Practice $(n=340)$

\begin{tabular}{|c|c|c|c|}
\hline \multirow{2}{*}{$\begin{array}{l}\text { First fluid given to a new } \\
\text { born }\end{array}$} & \multicolumn{3}{|c|}{ Exclusive breast feeding practice } \\
\hline & Yes \% & No \% & Total \% \\
\hline \multirow{2}{*}{ Breast milk only } & 1 & 43 & 44 \\
\hline & $2.3 \%$ & $97.7 \%$ & $100.0 \%$ \\
\hline \multirow{2}{*}{ Breast milk and warm water } & 1 & 24 & 25 \\
\hline & $4.00 \%$ & $96.00 \%$ & $100.00 \%$ \\
\hline \multirow{2}{*}{ Warm water only } & 19 & 76 & 95 \\
\hline & $20.00 \%$ & $80.00 \%$ & $100.00 \%$ \\
\hline \multirow{2}{*}{$\begin{array}{l}\text { Warm water containing utazi } \\
\text { leaf (Gongronema Latifolium) }\end{array}$} & 2 & 46 & 48 \\
\hline & $4.20 \%$ & $95.80 \%$ & $100.00 \%$ \\
\hline \multirow{2}{*}{ Artificial milk } & 0 & 5 & 5 \\
\hline & $0.00 \%$ & $100.00 \%$ & $100.00 \%$ \\
\hline \multirow{2}{*}{$\begin{array}{l}\text { Warm water containing agbeilu } \\
\text { nut (bitter kola/Garcinia Kola) }\end{array}$} & 22 & 68 & 90 \\
\hline & $37.50 \%$ & $62.50 \%$ & $100.00 \%$ \\
\hline \multirow{2}{*}{ Gripe water } & 0 & 1 & 1 \\
\hline & $0.00 \%$ & $100.00 \%$ & $100.00 \%$ \\
\hline \multirow{2}{*}{$\begin{array}{l}\text { Water containing Ochamala } \\
\text { root extract }\end{array}$} & 0 & 3 & 3 \\
\hline & $0.00 \%$ & $100.00 \%$ & $100.00 \%$ \\
\hline \multirow{2}{*}{$\begin{array}{l}\text { Water containing Nchuawu } \\
\text { (Ocimum Gratissimum) extract }\end{array}$} & 1 & 6 & $7.00 \%$ \\
\hline & $14.30 \%$ & $85.70 \%$ & $100.00 \%$ \\
\hline \multirow{2}{*}{ Water with palm fruit extract } & 0 & 13 & $13.00 \%$ \\
\hline & $0.00 \%$ & $100.00 \%$ & $100.00 \%$ \\
\hline \multirow{2}{*}{ *Others } & 0 & 9 & 9 \\
\hline & $0.00 \%$ & $100.00 \%$ & $100.00 \%$ \\
\hline \multirow{2}{*}{ Total } & 46 & 294 & $340.00 \%$ \\
\hline & $13.50 \%$ & $86.50 \%$ & $100.00 \%$ \\
\hline Chi-square value 30.66 & \multicolumn{2}{|c|}{ Degree of freedom 12} & $\mathrm{p}$-value $0.00 \mathrm{I}$ \\
\hline
\end{tabular}

\section{Timing of first fluid given to new born infant and the adoption EBF practice by nursing-mother}

Table 2 showed that $227(66.8 \%)$ of the nursing-mothers reported that the timing of first fluid/feed given to the new born infant was within thirty minutes of birth, 18(5.3\%) said fifteen minutes after delivery, 35(10.8\%) said within three hours, 39(11.5\%) said within 24 hours of birth, 14(4.1\%) mothers said that fluid was delayed till the next day after birth, while $7(2.1 \%)$ said more than twodays. None of those nursing-mothers who said that the time of introducing first fluid/ feed to the new born infant in their community was within 15 minutes after delivery practised EBF. Similarly, none of the nursing-mothers who said that the infant was introduced to fluid the next day after birth practised EBF. Thirty-seven (16.3\%) out of the 227 nursing-mothers who said within 30 minutes of birth the infant was introduced to fluid practised EBF. Seven nursing-mothers $(20.0 \%)$ out of 35 who said within 3 hours practised EBF. Only one nursing-mother (2.6\%) out of 39 who said within 24 hours of child birth fluid/feed was introduced to the new born infant, practised $\mathrm{EBF}$, while only one $(14.3 \%)$ out of 7 nursing-mothers who said fluid/feed was introduced more than 2days after delivery practised EBF. The time of giving first feed/fluid to the new born infant had significant relationship with the nursingmother's adoption of EBF practice as shown in Table 2 (chi square value $=11.76, \mathrm{df}=5, \mathrm{P}$-value $=0.04$ )

Table 2 Time of introducing first fluid to new born infant and the adoption of EBF practice by the nursing mothers

\begin{tabular}{|c|c|c|c|}
\hline \multirow{2}{*}{$\begin{array}{l}\text { Time of first fluid to new } \\
\text { born }\end{array}$} & \multicolumn{3}{|c|}{ Exclusive breast feeding practice } \\
\hline & Yes \% & No\% & Total \% \\
\hline \multirow{2}{*}{ Within 15 mins of delivery } & 0 & 18 & 18 \\
\hline & $0.00 \%$ & $100.00 \%$ & $100.00 \%$ \\
\hline \multirow{2}{*}{ Within 30 mins of delivery } & 37 & 190 & 227 \\
\hline & $16.30 \%$ & $83.70 \%$ & $100.00 \%$ \\
\hline \multirow{2}{*}{ Within 3hours of delivery } & 7 & 28 & 35 \\
\hline & $20.00 \%$ & $80.00 \%$ & $100.00 \%$ \\
\hline \multirow{2}{*}{ Within 24hours of delivery } & I & 38 & 39 \\
\hline & $2.60 \%$ & $97.40 \%$ & $100.00 \%$ \\
\hline \multirow{2}{*}{ The next day after delivery } & 0 & 14 & 14 \\
\hline & $0.00 \%$ & $100.00 \%$ & $100.00 \%$ \\
\hline \multirow{2}{*}{ More than 2 days after delivery } & I & 6 & 7 \\
\hline & $14.30 \%$ & $85.70 \%$ & $100.00 \%$ \\
\hline \multirow{2}{*}{ Total } & 46 & 294 & 340 \\
\hline & $13.50 \%$ & $86.50 \%$ & $100.00 \%$ \\
\hline Chi-square value 11.76 & \multicolumn{2}{|c|}{ Degree of freedom 5} & $\mathrm{p}$-value 0.04 \\
\hline
\end{tabular}

Usual duration for weaning an infant in the community and the adoption EBF practice by nursing-mothers

Forty-eight $(14.1 \%)$ of the respondents said the duration of breastfeeding before commencing weaning was one month and only one $(2.1 \%)$ of them practised EBF. Nine $(2.6 \%)$ said 2 months and only one (11.1\%) practised EBF. Others were; $70(20.6 \%)$ said 3 months and $7(10.0 \%)$ of them practised EBF, 74(21.8\%) said 4months and 3(4.1\%) practised EBF, 15(4.4\%) said 5months and $2(13.3 \%)$ practised EBF, 22(6.5\%) said 6months 3(13.6\%) practised EBF, 27(7.9\%) said 7months and 6(22.2\%) practised EBF, 42(12.4\%) said 8 months and $10(23.8 \%)$ practised $\mathrm{EBF}, 9(2.6 \%)$ said 9 months 
and $3(33.3 \%)$ practised EBF, $1(0.3 \%)$ said 11 months and none of them practised EBF, while 23(6.8\%) said 12 months and 10(43.5\%) of them practised EBF. Duration of weaning an infant as stated by the respondents was significantly related to nursing-mothers' adoption of EBF practice as shown in Table 3 (chi-square $=38.19, \mathrm{df}=10$ and $\mathrm{P}<$ $0.0001)$.

Table 3 Usual duration of weaning an infant in the community and adoption of EBF practice by nursing-mothers $(n=340)$

\begin{tabular}{|c|c|c|c|}
\hline \multirow{3}{*}{$\begin{array}{l}\text { Usual duration of weaning } \\
\text { an infant } \\
\text { in the community(In } \\
\text { months) }\end{array}$} & \multicolumn{3}{|c|}{$\begin{array}{l}\text { Exclusive breast feeding } \\
\text { practice }\end{array}$} \\
\hline & Yes & No & Total \\
\hline & $\%$ & $\%$ & $\%$ \\
\hline \multirow{2}{*}{ I } & 1 & 47 & 48 \\
\hline & $2.10 \%$ & $97.90 \%$ & $100.00 \%$ \\
\hline \multirow{2}{*}{2} & 1 & 8 & 9 \\
\hline & $11.10 \%$ & $88.90 \%$ & $100.00 \%$ \\
\hline \multirow{2}{*}{3} & 7 & 63 & 70 \\
\hline & $10.00 \%$ & $90.00 \%$ & $100.00 \%$ \\
\hline \multirow{2}{*}{4} & 3 & 71 & 74 \\
\hline & $4.10 \%$ & $95.90 \%$ & $100.00 \%$ \\
\hline \multirow{2}{*}{5} & 2 & 13 & 15 \\
\hline & $13.30 \%$ & $86.70 \%$ & $100.00 \%$ \\
\hline \multirow{2}{*}{6} & 3 & $19.00 \%$ & 22 \\
\hline & $13.60 \%$ & $86.40 \%$ & $100.00 \%$ \\
\hline \multirow{2}{*}{7} & 6 & $21.00 \%$ & 27 \\
\hline & $22.20 \%$ & $77.80 \%$ & $100.00 \%$ \\
\hline \multirow{2}{*}{8} & 10 & $32.00 \%$ & 42 \\
\hline & $23.80 \%$ & $76.20 \%$ & $100.00 \%$ \\
\hline \multirow{2}{*}{3} & 3 & 6 & 9 \\
\hline & $33.30 \%$ & $66.70 \%$ & $100.00 \%$ \\
\hline \multirow{2}{*}{ II } & 0 & I & I \\
\hline & $0 \%$ & $100.00 \%$ & $100.00 \%$ \\
\hline \multirow{2}{*}{12} & 10 & 13 & 23 \\
\hline & $43.50 \%$ & $56.50 \%$ & $100.00 \%$ \\
\hline \multirow{2}{*}{ Total } & 46 & 294 & 340 \\
\hline & $13.50 \%$ & $86.50 \%$ & $100.00 \%$ \\
\hline Chi-square value 38.19 & \multicolumn{2}{|c|}{ Degree of freedom 10} & $\begin{array}{l}\text { P-value } \\
<0.000 \text { I }\end{array}$ \\
\hline
\end{tabular}

Beliefs about colostrum in the community and the adoption EBF practice by nursing-mothers

Sixty-two (18.2\%) respondents said that colostrum boosts intelligence, $88(25.9 \%)$ said that the first yellow milk (colostrum) stimulates growth/health, 60(17.6\%) said development of immune system, $12(3.5 \%)$ said to develop good sight, 42(12.4\%) gives strong bone, $52(15.3 \%)$ food for the child, $16(4.7 \%)$ prevents infection, $6(1.8 \%)$ causes diarrhoea, and 2(0.6\%) simply said they did not like colostrum. Out of the 62 nursing-mothers who stated that colostrum boosts intelligence of the child only $8(12.9 \%)$ practised EBF, $17(19.3 \%)$ out of 88 that said that colostrum stimulate growth practised EBF, $6(10.0 \%)$ out of 60 that said it helps in developing immune system practised EBF, none of the 12 that said it aids in development of good sight practised EBF, $8(19 \%)$ out of 42 who said colostrum gives strong bones practised EBF, 2(3.8\%) out of 52 who said colostrum is food for the new born infant practised EBF, 2(12.5\%) out of 16 who stated that it prevents infections practised EBF, while 2(33.3\%) out of 6 respondents who said colostrum causes diarrhoea practised EBF and one $(50 \%)$ out of the two nursing-mothers whose response was 'I don't like colostrum' practised EBF. Beliefs about colostrum had no significant relationship with nursing- mothers' adoption of EBF practice as shown in Table 4, (chi value $=14.62, \mathrm{df}=8$ and $\mathrm{P}=0.067$ ).

Table 4 Beliefs about the first yellow milk produced by the breast (colostrum) and nursing-mothers' adoption of EBF practice $(n=340)$

\begin{tabular}{|c|c|c|c|}
\hline \multirow{3}{*}{$\begin{array}{l}\text { Belief about } \\
\text { first yellow milk } \\
\text { produced by the } \\
\text { breast(Colostrum) }\end{array}$} & \multicolumn{3}{|c|}{$\begin{array}{l}\text { Exclusive milk breast feeding } \\
\text { practice }\end{array}$} \\
\hline & Yes & No & Total \\
\hline & $\%$ & $\%$ & $\%$ \\
\hline \multirow{2}{*}{ Boosts intelligence } & 8 & 54 & 62 \\
\hline & $12.90 \%$ & $87.10 \%$ & $100.00 \%$ \\
\hline \multirow{2}{*}{$\begin{array}{l}\text { Stimulates growth/ } \\
\text { health }\end{array}$} & 17 & 71 & 88 \\
\hline & $19.30 \%$ & $80.70 \%$ & $100.00 \%$ \\
\hline \multirow{2}{*}{$\begin{array}{l}\text { Develops immune } \\
\text { system }\end{array}$} & 6 & 54 & 60 \\
\hline & $10.00 \%$ & $90.00 \%$ & $100.00 \%$ \\
\hline \multirow{2}{*}{ Develops good sight } & 0 & 12 & 12 \\
\hline & $0.00 \%$ & $100.00 \%$ & $100.00 \%$ \\
\hline \multirow{2}{*}{ Gives strong bones } & 8 & 34 & 42 \\
\hline & $19.00 \%$ & $81.00 \%$ & $100.00 \%$ \\
\hline \multirow{2}{*}{ Food for the child } & 2 & 50 & 52 \\
\hline & $3.80 \%$ & $96.20 \%$ & $100.00 \%$ \\
\hline \multirow{2}{*}{ Prevents infections } & 2 & 14 & 16 \\
\hline & $12.50 \%$ & $87.50 \%$ & $100.00 \%$ \\
\hline \multirow{2}{*}{ Causes diarrhoea } & 2 & 4 & 6 \\
\hline & $33.30 \%$ & $66.70 \%$ & $100.00 \%$ \\
\hline \multirow{2}{*}{ I don't like it } & I & I & 2 \\
\hline & $50.00 \%$ & $50.00 \%$ & $100.00 \%$ \\
\hline \multirow{2}{*}{ Total } & 46 & 294 & 340 \\
\hline & $13.50 \%$ & $86.50 \%$ & $100.00 \%$ \\
\hline $\begin{array}{l}\text { Chi-square value } \\
14.62\end{array}$ & \multicolumn{2}{|c|}{ Degree of freedom 8} & $\begin{array}{l}\text { P-value } \\
0.067\end{array}$ \\
\hline
\end{tabular}

Most popular practice of infant feeding in the first sixmonths and adoption of EBF by nursing-mothers

Table 5 showed the results of most popular practice of infant feeding in the first sixmonths in the community and nursing-mothers' adoption of EBF practice. Majority of the respondents $254(74.7 \%)$ stated that the most popular practice of infant feeding in the first 6 months was breastfeeding with only water as addition. Forty-five $(17.7 \%)$ out of the 254 respondents in this category practised EBF. Eight-five (25\%) respondents stated that breastfeeding with additions such as glucose drinks, water and traditional herbs was the most popular. Out the 85 nursing-mothers who responded in this category only one $(1.2 \%)$ practised EBF. Only one $(0.3 \%)$ respondent said 
exclusive breastfeeding was the most popular practice of infant feeding in the first sixmonths of birth but this respondent did not practise EBF ( $0 \%$ EBF practice). The most popular practice of infant feeding in the community in the first sixmonths of infant life had significant relationship with nursing- mothers' adoption of EBF as shown in Table 5 (chi-square $=15.05, \mathrm{df}=2, \mathrm{P}=0.001$ ). ${ }^{1}$

Table 5 Most popular practice of infant feeding in the first six months of birth and nursing-mothers' adoption of EBF practice $(n=340)$

\begin{tabular}{|c|c|c|c|}
\hline \multirow{3}{*}{$\begin{array}{l}\text { Most popular practice of } \\
\text { infant feeding in the } \\
\text { community in the first six } \\
\text { months of birth }\end{array}$} & \multicolumn{3}{|c|}{ Exclusive breast feeding practice } \\
\hline & Yes & No & Total \\
\hline & $\%$ & $\%$ & $\%$ \\
\hline \multirow{2}{*}{$\begin{array}{l}\text { Breastfeeding child with only } \\
\text { water as addition }\end{array}$} & 45 & 209 & 254 \\
\hline & $17.70 \%$ & $82.3 \%$ & $100.0 \%$ \\
\hline \multirow{2}{*}{$\begin{array}{l}\text { Breastfeeding child and giving } \\
\text { other fluids (eg glucose water, } \\
\text { traditional herbs) }\end{array}$} & 1 & 84 & 85 \\
\hline & $1.20 \%$ & $98.80 \%$ & $100.00 \%$ \\
\hline \multirow{2}{*}{$\begin{array}{l}\text { Exclusive breastfeeding (EBF) } \\
\text { (giving only breast milk to child } \\
\text { without giving any other fluid) }\end{array}$} & 0 & I & I \\
\hline & $0 \%$ & $100.00 \%$ & $100.00 \%$ \\
\hline \multirow{2}{*}{ Total } & 46 & 294 & 340 \\
\hline & $13.50 \%$ & $86.50 \%$ & $100.00 \%$ \\
\hline Chi-square value 15.05 & \multicolumn{2}{|c|}{ Degree of freedom 2} & $P$-value 0.001 \\
\hline
\end{tabular}

\section{If culture opposed EBF and adoption of EBF practice by nursing-mothers}

Results of if culture opposed EBF and nursing-mothers' adoption of EBF practice were reflected in Table 6. Fifty-three $(15.6 \%)$ nursing-mothers out of the 340 respondents said their culture opposed EBF and 5 (9.4\%) out of these respondents practised EBF. Out of the $287(84.4 \%)$ respondents who said their culture did not oppose EBF, only $41(14.3 \%)$ practised EBF. If culture opposed EBF practice was not significantly related to the adoption of EBF practice by nursingmothers as shown in Table 6 (chi-square $=0.90, \mathrm{df}=1, \mathrm{P}=0.34$ ).

Table 6 If culture opposed EBF and nursing-mothers' adoption of EBF practice $(n=340)$

\begin{tabular}{llll}
\hline \multirow{2}{*}{$\begin{array}{l}\text { Does your culture } \\
\text { oppose EBF }\end{array}$} & \multicolumn{4}{l}{ Exclusive breast feeding practice } \\
\cline { 2 - 4 } & Yes & No & Total \\
\cline { 2 - 4 } & $\%$ & $\%$ & $\%$ \\
\hline Yes & 5 & 48 & 53 \\
& $9.40 \%$ & $90.60 \%$ & $100.00 \%$ \\
No & 41 & 246 & 287 \\
& $14.30 \%$ & $85.70 \%$ & $100.00 \%$ \\
Total & 46 & 294 & 340 \\
Chi-square value 0.90 & Degree of freedom I & P-value 0.034 \\
\hline
\end{tabular}

Reasons for saying culture opposed EBF and adoption of EBF practice by nursing-mothers

Out of the 53 nursing-mothers who said that their culture opposed EBF $10(18.9 \%)$ respondents said it was because EBF was not good for the child and only one (10\%) of them practised EBF. Nineteen $(35.8 \%)$ said EBF was alien and not their cultural practice. Only $1(5.3 \%)$ nursing-mother out of these 19 practised EBF. Nine (17\%) respondents gave their reason as non-availability of nursing mothers for this practice and just $2(22.2 \%)$ of respondents in this group practised EBF. Fifteen (28\%) out of the total respondents could not advance any particular reason for saying culture was opposed to EBF and only one (6.7\%) respondent in this category practised EBF. There was no significant relationship between the reasons given by nursing-mothers for culture opposing EBF and the adoption of EBF by nursing-mothers as shown in Table $7(\mathrm{P}=0.52)$.

Table 7 Reasons for saying that culture opposed or did not oppose EBF, and nursing-mothers adoption of EBF practice $(n=340)$

\begin{tabular}{|c|c|c|c|}
\hline \multirow{3}{*}{$\begin{array}{l}\text { Reason for saying } \\
\text { culture opposed EBF }\end{array}$} & \multicolumn{3}{|c|}{ Exclusive breast feeding practice } \\
\hline & Yes & No & Total \\
\hline & $\%$ & $\%$ & $\%$ \\
\hline \multirow{2}{*}{ Not good for the child } & 1 & 9 & 10 \\
\hline & $10.00 \%$ & $90.00 \%$ & $100.00 \%$ \\
\hline \multirow{2}{*}{ Not our culture } & 1 & 18 & 19 \\
\hline & $5.30 \%$ & $94.70 \%$ & $100.00 \%$ \\
\hline \multirow{2}{*}{$\begin{array}{l}\text { Unavailability of the } \\
\text { mother }\end{array}$} & 2 & 7 & 9 \\
\hline & $22.20 \%$ & $77.80 \%$ & $100.00 \%$ \\
\hline \multirow{2}{*}{ No reason } & 1 & $14.00 \%$ & 15 \\
\hline & $6.70 \%$ & $93.30 \%$ & $100.00 \%$ \\
\hline \multirow{2}{*}{ Total } & 5 & 48 & 53 \\
\hline & $9.40 \%$ & $90.60 \%$ & $100.00 \%$ \\
\hline Chi-square value 2.25 & \multicolumn{2}{|c|}{ Degree of freedom 3} & $P$-value 0.52 \\
\hline
\end{tabular}

\section{Focus group discussion (FGD)}

The groups discussed constraints to exclusive breastfeeding practice. The discussion revealed that most nursing-mothers did not practice exclusive breastfeeding. A mother said, "Breast milk is the first fluid to give but when breast milk is not ready then water is given because baby will not starve and time to start feeding new born depends on when the infants demands for it, which the baby often signifies by crying". Another mother said, "We breastfeed our babies but with addition. For us not to give water to the infant is unimaginable". Another mother said "Babies suffer abdominal colic and need medicinal fluids. The medicinal herbs and roots which are given to babies are very good remedies for their abdominal colic. Abdominal colic is very common among new born and does not respond well to orthodox medicine". Another mother said "Breast milk alone cannot be adequate for the infant so I give baby pap from as early as twomonths". Another said "We mothers are busy and not always at home (quotes are researchers' translation from the Igbo language used by the mothers).

\section{Discussion}

Percentage EBF practice was very low among nursing-mothers in the selected communities (13.5\%). EBF was very low among all age groups and did not maintain any particular pattern as to attribute the difference observed to age. However, those in age group 15-19years had slightly higher EBF practice than the rest. This group of nursing- 
mothers could be described as inexperience in child bearing and child rearing, which might make them adhere to some extent to health workers directive regarding EBF.

Breast milk should be the first fluid/feed given to the infant but most nursing-mothers did not give breast milk to their new born as the first fluid/feed. Water or water containing medicinal herbs/roots was the first fluid/feed given. Nursing-mothers response did not reflect their adoption of EBF practice, for instance 97.7 percent of those who said that breast milk was the first fluid given to infants did not practice EBF. The respondents believed that water with medicinal herbs or roots were efficacious in the treatment of abdominal colic experienced by infants. New born infant should be introduced to the breast within 30 minutes of birth and majority of the respondents stated so but 83.3 percent of those who said that did not practice EBF. Some mothers waited for up to 24 hours or more to give first fluid/feed to the new born. There was an indication of gap between knowledge and practice. Their response might be based on information on EBF given by health workers at the health facilities. EBF knowledge in this instance was not a sufficient factor to influence practice, indicating the existence of a strong underlying restraining factor which could be traced to cultural practices. This corroborated with other findings, for example, the Hmong people of Laos waited till they perceive the infant to be 'ready' for feed which might be after some bowel motions or the infant was more alert and active. ${ }^{26}$ The process of weaning an infant should start at six months which should mark the end of EBF and the introduction of complimentary feed, though breastfeeding should continue till twoyears. ${ }^{10}$ Majority of the nursing mothers reported duration breastfeeding before commencing weaning as 4 months. The duration stated by the respondents was between one month and 12 months but all had very low percentage EBF practice. Duration of breast feeding before weaning was statistically significant with adoption of adoption of EBF by the nursing-mothers. This aligned with traditional and cultural practices where weaning usually started earlier than six months. Most of the nursing-mothers who breastfed their infants did so with additions which had its root in traditional infant feeding practices. The respondents believed that these additions such as water and supplementary feeds were beneficial to the infant which aligned with the findings of Agunbiade and Ogunleye, ${ }^{17}$ Davies-Adetugbo. ${ }^{20}$ The early commencement of weaning recorded also agreed with the practice in Kenya, ${ }^{22}$ in Peru ${ }^{23}$ and in certain European cultures. ${ }^{24}$ Majority of the respondents stated that colostrum was beneficial to the infant, but both those stated that colostrum was beneficial and those who stated otherwise had low EBF practice. Belief about colostrum was not statistically significant with adoption of EBF by nursing mothers. Belief about colostrum therefore did not impact on EBF practice of the respondents, signalling that breastfeeding practice should be addressed as an embodied cultural behaviour. Only one respondent stated that the most popular practice of infant feeding in the communities was EBF and this respondent did not practice EBF. The rest had very low percentage of EBF. This is a clear indication of non-adoption of EBF in the communities. Most popular practice of infant feeding in the first 6months of infant life was statistically significant. This was in agreement with several studies that showed low EBF globally.

Majority (287) respondents said their culture did not oppose EBF. Both those who responded in the affirmative and those who did not, had very low EBF practice and this was a surprise, because one would naturally feel that those who were of the opinion that culture did not oppose EBF would practice EBF. The responses recorded here revealed discord in knowledge and practice. Culture opposing EBF was not significantly related to adoption of EBF practice. Reasons advanced by the respondents for culture opposing EBF were views that were not substantiated or backed by facts but tales and fables. The response of mothers not being available to practice EBF pointed to the culture where mothers were engaged in economic activities outside the home and might not move about with their infants necessitating supplementary feeding. However, research findings had shown that even mothers who were not engaged in work outside their home had very low percentage of exclusive breastfeeding practice puncturing this reason given for low EBF. Infant feeding practice such as breastfeeding practice had been with the people since time immemorial and had traditionally been handed over to mothers as good practice which was tenaciously held. Reasons for culture opposing EBF showed no significant relationship with the adoption of EBF practice by nursing mothers. Responses from mothers during FGD revealed that most nursing-mothers did not practice EBF because of some reasons that hinged on beliefs and cultural practices that had been their tradition. The constraints elicited aligned with results gotten from the quantitative data.

\section{Conclusion}

Percentage exclusive breastfeeding practice was low, 13.5\%. This did not differ from the Nigerian national value of $13 \%$ as determined about a decade ago. Progress in the adoption of EBF had been slow and the reason might be partly because breastfeeding is an embodied practice that is strongly rooted in culture.

\section{Recommendations}

There is need to expand the strategies employed in EBF promotion and support to include those which will address cultural factors in EBF. Community leaders and gate keepers in the communities should constitute part of the drivers of this desired change. EBF promotion should not be limited to the health sector but should employ multisectorial approach involving counsellors, sociologists, community development officers, the media among others for sustained campaign for the promotion of exclusive breastfeeding practice.

\section{Ethical approval/informed consent}

Ethical approval was gotten from the Department of Sociology, Imo State University Owerri. Community leaders and the respondents gave informed consent for the study.

\section{Limitation}

Mothers who were absent at home when visited were not revisited due to time constraint but the percentage of respondents was representative enough and FGD enriched the findings.

\section{Acknowledgements}

None.

\section{Conflict of interest}

Author declares that there is no conflict of interest.

\section{References}

1. Stuart-Macadam P, Dettwyler KA. Breastfeeding: Biocultural perspectives. Hawthorne, Aldine de Cruyter, New York, USA; 1995.

2. Uchendu UO, Ikefuna AN, Emodi IJ. Factors associated with exclusive breastfeeding among mothers seen at the University of Nigeria Teaching Hospital. South African Journal of Child Health. 2009;3(1):14-19. 
3. Leiniger MM. Qualitative research methods in nursing. Orlando: Grunee and Stratton; 1985.

4. Matusiak MM. A cultural perspective of the feding habits. The Internet Journal of Nutrition and Wellness. 2005;1(2).

5. Global strategy for infant and young child feeding. World Health Organization (WHO) and UNICEF, Geneva, Switzerland; 2003

6. National Policy on Infant And Young Child Feeding. In Nigeria, Federal Ministry of Health, Nutrition Division, Abuja; 2003.

7. Ip S, Chung M, Raman G, et al. Breastfeeding and maternal and infant health outcomes in developed countries. Rockville, MD: US Department of Health and Human Services; 2007.

8. Indicators for assessing infant and young child feeding practices Washington D.C: World Health Organization (WHO); 2008.

9. Indicators for accessing breastfeeding practice. World Health Organization (WHO)/CDD/SER/, Geneva; 1991.

10. Report of the expert consultation on the optimal duration of exclusive breastfeeding: and recommendations. World Health Organization (WHO), Geneva; 2001.

11. Iliyasu Z, Kabir M, Abubakar IS, et al. Current knowledge and practice of exclusive breastfeeding among mothers in Gwale Local Government Area of Kano State. Nigerian Medical Practitioner. 2005;48:50-55.

12. Jones G, Steketee RW, Black RE, et al. How many child deaths can we prevent this year? Lancet. 2003;362:65-71.

13. Baumslag N, Michele DL. Milk, money, and madness: The culture and politics of breastfeeding. Westport, CT: Bergin and Garvey; 1995.

14. Data bank on infant and young child feeding in Nigeria. Nigeria: World Health Organization (WHO); 2010.

15. Nigeria Demographic \& Health Survey 2008 National Population Commission Federal Republic of Nigeria Abuja Nigeria, ICF Macro Calverton, Maryland, USA; 2008.

16. Chan SM, Nelson EA, Leung SS, et al. Breastfeeding failure in a longitudinal post-partum maternal nutritional study in Hong Kong. $J$ Paediatr Child Health. 2000;36(5):466-471.
17. Khin PP, Chaueng SL, Loh T. Support and promotion of breastfeeding: Where are we now? Public Health and Epidemiology Bulletin. 2002;930:25-32.

18. Agunbiade OM, Ogunleye OV. Constraints to exclusive breastfeeding mothers in south west Nigeria: Implications for scaling up. International Breastfeeding Journal. 2012;7(5).

19. Ludvigsson JF. Breastfeeding intentions, patterns and determinants in infants visiting hospitals in La Paz, Bolivia. BMC Pediatr. 2003;3(1):5.

20. Sika-Bright S. Socio-cultural factors influencing infant feeding practice of mothers attending welfare clinic in cape coast. French Embassy Small Grants Programme in the Humanities and Social Sciences. Accra; 2010.

21. Davies-Adetugbo AA. Sociocultural factors and the promotion of exclusive breastfeeding in rural Yoruba communities of Osun State. Soc Sci Med. 1997;45:113-125.

22. Patil SS, Hasamnis AA, Pathare RS, et al. Prevalence of exclusive breastfeeding and its correlates in an urban slum in western India. JSME. 2009;3(2):14-18.

23. Dimond HJ, Ashworth A. Infant feeding practices in Kenya, Mexico and Malaysia. Hum Nutr Appl Nutr. 1987;41(1):51-64.

24. Bertelsen C, Anerbach KG. Nutrition and breastfeeding: The cultural connection. Lactation Consultant Series. Franklin Park, IL, La Leche league; 1987.

25. Riordan JM. The cost of not breastfeeding: A commentary. J Hum Lact. 1997;13(2):93-97.

26. Van Esterik P. Contemporary trends in infant feeding research. Annual Review Anthropology. 2002;3(1):257-278.

27. Nelson CC, Hewitt MA. An IndoChinese refugeepopulation in a nursemidwife service. J Nurse Midwifery. 1983;28(5):9-14.

28. Global strategy for infant and young child feeding. Geneva: World Health Organization (WHO); 2001. 